\title{
Microtiter plate-sized standalone chip holder for microenvironmental physiological control in gas- impermeable microfluidic devices
}

Citation for published version (APA):

Harink, B., Le Gac, S., Barata, D., van Blitterswijk, C., \& Habibovic, P. (2014). Microtiter plate-sized standalone chip holder for microenvironmental physiological control in gas-impermeable microfluidic devices. Lab on A Chip, 14(11), 1816-1820. https://doi.org/10.1039/c4lc00190g

Document status and date:

Published: 01/01/2014

DOI:

10.1039/c4lc00190g

Document Version:

Publisher's PDF, also known as Version of record

Document license:

Taverne

Please check the document version of this publication:

- A submitted manuscript is the version of the article upon submission and before peer-review. There can be important differences between the submitted version and the official published version of record.

People interested in the research are advised to contact the author for the final version of the publication, or visit the DOI to the publisher's website.

- The final author version and the galley proof are versions of the publication after peer review.

- The final published version features the final layout of the paper including the volume, issue and page numbers.

Link to publication

\footnotetext{
General rights rights.

- You may freely distribute the URL identifying the publication in the public portal. please follow below link for the End User Agreement:

www.umlib.nl/taverne-license

Take down policy

If you believe that this document breaches copyright please contact us at:

repository@maastrichtuniversity.nl

providing details and we will investigate your claim.
}

Copyright and moral rights for the publications made accessible in the public portal are retained by the authors and/or other copyright owners and it is a condition of accessing publications that users recognise and abide by the legal requirements associated with these

- Users may download and print one copy of any publication from the public portal for the purpose of private study or research.

- You may not further distribute the material or use it for any profit-making activity or commercial gain

If the publication is distributed under the terms of Article $25 \mathrm{fa}$ of the Dutch Copyright Act, indicated by the "Taverne" license above, 


\title{
Lab on a Chip
}

\section{Microtiter plate-sized standalone chip holder for microenvironmental physiological control in gas-impermeable microfluidic devices $\uparrow$}

\author{
Björn Harink, ${ }^{a}$ Séverine Le Gac, ${ }^{\text {b }}$ David Barata, ${ }^{a}$ Clemens van Blitterswijk $^{a}$ \\ and Pamela Habibovic*a
}

Received 12th February 2014,

Accepted 20th March 2014

DOI: $10.1039 / c 4 l c 00190 \mathrm{~g}$

www.rsc.org/loc

\begin{abstract}
We present a microtiter plate-sized standalone chip holder for precise control of physiological conditions inside closed microfluidic cell culture systems, made from gas-impermeable materials. Specifically, we demonstrate the suitability of the holder to support cell growth in a glass chip, to allow time-lapse imaging of live cells and the creation of a hypoxic environment, all relevant for applications in regenerative medicine research.
\end{abstract}

Microfluidic systems are successfully applied to create tailored chemical and physical microenvironments with high fidelity at the micrometre scale, enabling in-depth analysis of cell behaviour, in a milieu that mimics their natural biological environment. ${ }^{1}$ As such, microfluidic systems have become highly relevant tools for fundamental (cell) biological studies, diagnostics, and pharmacological screens. Furthermore, as we recently discussed, microfluidic systems may become widely used in regenerative medicine (RM) research. ${ }^{2}$ Microfluidics based in vitro systems for RM research should allow for tailoring of the biological environment by controlling gas-exchange, temperature, $\mathrm{pH}$, nutrient supply, and metabolite removal. Another important aspect to be taken into account when developing such a system is the possibility to perform continuous and real-time assays, for example, based on live or time-lapse imaging, increasing therewith the throughput of screening. Finally, such systems are preferably compatible with standard laboratory equipment, such as microscopes and plate readers.

The majority of currently applied microfluidic systems intended for biological studies are made from polydimethylsiloxane (PDMS). PDMS has the advantage of being gaspermeable, and therefore cells grown in PDMS based systems can be cultured using conventional laboratory incubators. ${ }^{3-5}$ Furthermore, PDMS is relatively inexpensive and its fabrication is straightforward. ${ }^{6}$ The use of PDMS is, however, also

\footnotetext{
${ }^{a}$ Department of Tissue Regeneration, MIRA Institute for Biomedical Technology and Technical Medicine, Enschede, The Netherlands.

E-mail: bjornharink@gmail.com, p.habibovic@utwente.nl; Fax: +31 53489 2150; Tel: +31534893400

${ }^{b}$ BIOS, The Lab-on-a-Chip Group, MESA+ Institute for Nanotechnology, University of Twente, Enschede, The Netherlands

$\dagger$ Electronic supplementary information (ESI) available. See DOI: 10.1039/ c4lc00190g
}

associated with important drawbacks, such as limited fluidic control due to the porous nature of the material and unpredictable and unstable surface chemistry. ${ }^{7}$ Furthermore, severe concerns are shared by many biologists regarding the incomplete biological characterization of the effects of this material. ${ }^{7}$ Other materials that are better characterized from this perspective, such as glass and polystyrene (PS), owing to their widespread use in conventional in vitro systems, exist. ${ }^{7}$ However, they are not or poorly gas-permeable, which limits their applicability to closed cell-culture systems, where $\mathrm{CO}_{2}$ and $\mathrm{O}_{2}$ must be tightly regulated. Closed in vitro systems are of particular importance in the RM research, where, among others, interactions of cells with various natural and synthetic biomaterials are studied, the majority of which are gas-impermeable. ${ }^{2,8}$ Such closed systems require alternative ways to control physical parameters inside the cell culture device, for example, in the form of a standalone incubator.

Current commercially available standalone culture systems, such as microscope stage incubators (e.g. Okolab, Pecon), are bulky, limiting control of the microenvironment. In addition, they require modifications of the microscope, and they are dedicated, not portable, and do not readily accommodate microfluidic connections. Systems that facilitate microfluidic connections do not allow for control of temperature and gas conditions in closed systems (e.g. Micronit, microLIQUID) or are mainly meant for PDMS cell culture devices. ${ }^{9-11}$

To overcome these issues, we have developed a platform in which entirely closed microfluidic systems made from gas-impermeable materials can be used for cell culture under varying physiological conditions. The complete system consists of a glass microfluidic chip inserted into a microtiter plate-sized chip holder, which also functions as a standalone incubator, allowing gas-tension and temperature control. The system is suitable for in situ time-lapse or live imaging of 
cells and is compatible with standard laboratory (imaging) equipment. Control on the gas composition inside the glass cell culture chip is achieved by using gas-permeable tubing inside the closed chip holder. As such, the system supports cell growth, but it can also be used to mimic deviating physiological conditions, such as oxygen deprivation, also known as hypoxia.

\section{Chip holder}

The chip holder consists of an aluminium chamber, into which the chip can be inserted, allowing for fluidic interfacing using a manifold connected to an array of capillaries. The whole platform was designed, fabricated and assembled in-house. Aluminium was chosen for its high thermal conductivity and machinability. The whole aluminium chamber is used as a heat sink and is kept at a stable temperature using two square $20 \mathrm{~mm}$ Peltier elements (MULTICOMP, Farnell, The Netherlands) placed on either side of the chamber, and each contains an attached outer heat sink (Fig. 1A). The chamber and heat sinks are thermally insulated using polyoxymethylene (POM) spacers. Since the whole device is precision milled, it is fully symmetrical and involves a relatively small temperature difference $(37-\mathrm{RT}=12 \mathrm{~K})$, with negligible temperature gradient over a distance of $1 \mathrm{~mm}$, as measured using conventional probes $\left(< \pm 0.05{ }^{\circ} \mathrm{C}\right)$. To ensure stable temperature and fast response, the Peltier elements are powered by a computer programmable controller, capable of delivering pulse-width modulated and polarizable output (TCM, Electro Dynamics Ltd., Southampton, United Kingdom). The feedback temperature sensor (NTC) is placed on the side of the chip (Fig. 1B-C) so as not to block the light, and an offset of $0.8 \mathrm{~K}$ was determined using an external temperature probe near the micro-chamber. This resulted in a stable temperature at a desired value $\left(37^{\circ} \mathrm{C}\right)$ with a tested SD of $\pm 0.003{ }^{\circ} \mathrm{C}$ over a period of $20 \mathrm{~h}$. This feature is particularly important for the stability of the cell culture and imperative for the stability and predictability of the fluidics.

Gas exchange is ensured through the microfluidic connections with the chip inside the closed chip holder, using perfluoroalkoxy (PFA) capillaries $(150 \mu \mathrm{m}$ ID and $360 \mu \mathrm{m}$ OD PFA HP Plus, DuPont, USA), each having an internal volume of $6 \mu \mathrm{L}$ (Fig. 1B-C). By controlling the flow rate through the tubing, the residence time of the medium inside the tubing can be set to ensure that gas equilibrium is reached before the medium enters the chip (for detailed calculation to determine minimum residence time, please see ESI $\dagger$ ). Fused silica capillaries (200 $\mu \mathrm{m}$ ID and $360 \mu \mathrm{m}$ OD, PolyMicro, France) are used for outlet connections and collection of (waste) medium, since the medium is passed only once. Even though fluoropolymers are not known for their inherent gaspermeability, they provide a good compromise between chemical resistance, thermal stability and gas exchange. The gas mixture is provided by $5 \% \mathrm{CO}_{2}$ supplemented compressed air (Linde Group, The Netherlands) and reduced oxygen mixture is obtained by partial mixing with $\mathrm{N}_{2}$. To provide sufficient humidity, to avoid possible evaporation through the PFA tubing

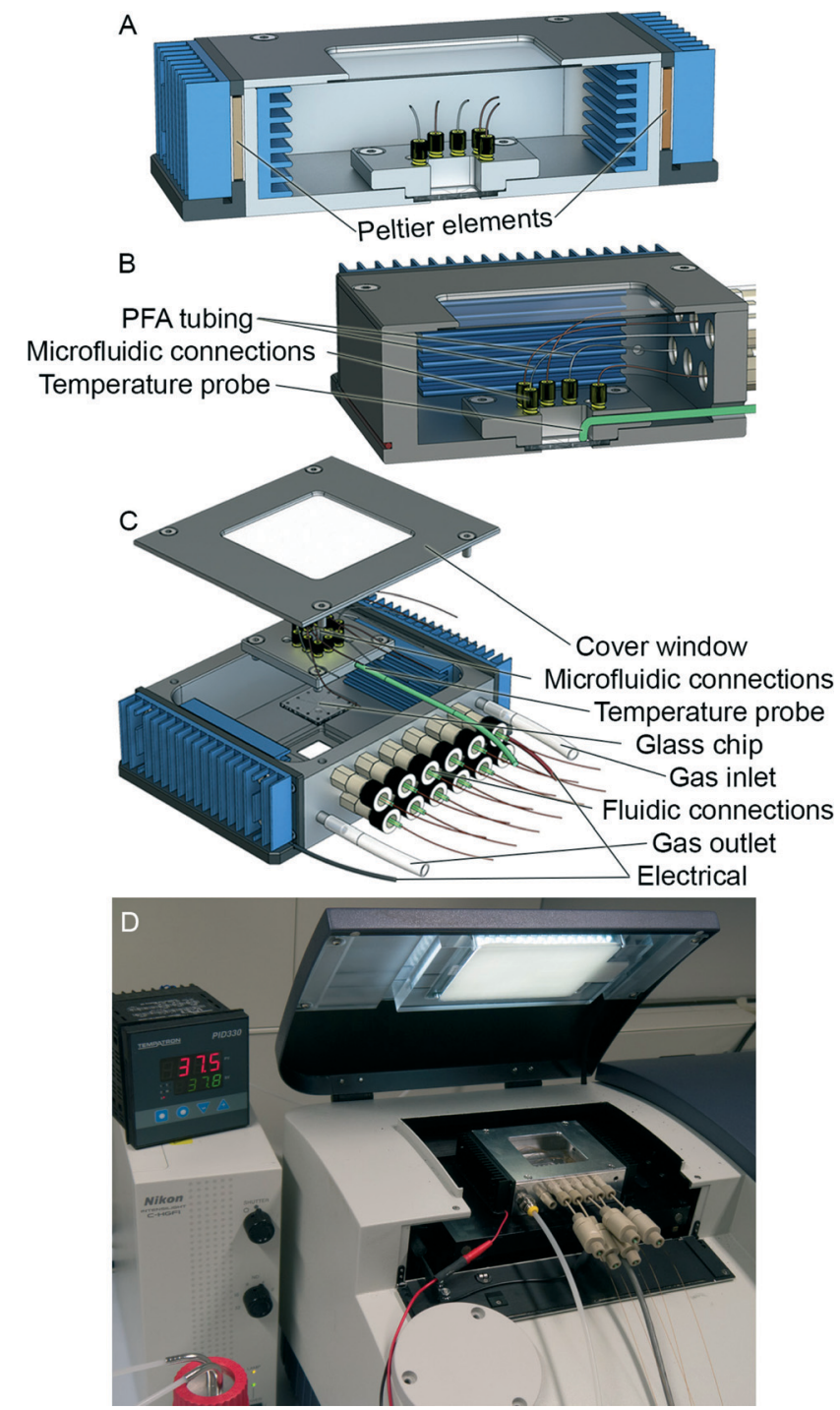

Fig. 1 (A) Schematic depiction of a longitudinal cut-through of the chip-holder, showing the position of the two Peltier elements and heat sinks. (B) Depiction of a transverse cut-through, showing the position of the temperature probe, the chip, and its connections to the gas-permeable PFA tubing. (C) Exploded view, showing the different separable parts. The lid includes a glass window for top illumination for contrast microscopy. (D) Picture of the chip holder inside a microtiter plate microscope with electrical, gas and fluidic connections. The bottle in the bottom left corner is the bubbler to keep the humidity high to prevent evaporation through the gas-permeable tubing.

(Fig. 1D), the gas mixture is flown through a water bubbler before entering the chip holder.

The whole platform has the footprint of a microtiter plate $(127.5 \mathrm{~mm} \times 85.5 \mathrm{~mm})$ and a height of $32 \mathrm{~mm}$. These dimensions make it compatible with a variety of read-out equipment meant for microtiter plates. For live imaging, the chip holder is placed in a microtiter plate microscope (BD Pathway 435, USA) capable of fully automated fluorescence and bright-field microscopy (Fig. 1D) or in a fully automated DIC/confocal microscope (NIKON Ti-Eclipse with A1 confocal, Japan). 


\section{Glass chips}

Two different chip designs were tested to demonstrate the effectiveness of the platform: (i) a device with two $650 \mu \mathrm{m} \times$ $4 \mathrm{~mm}$ rectangular chambers connected to two supply channels (Fig. 2A), via an array of $1 \mu \mathrm{m} \times 3 \mu \mathrm{m} \times 10 \mu \mathrm{m}$ channels; and (ii) a device with a $650 \mu \mathrm{m}$ square chamber surrounded by four supply channels (Fig. 2C), also connected to the chamber by a similar array of microchannels (Fig. 2D). Thereby, diffusion is dominant over convection between the channel and the chamber due to the high relative resistance of the connecting channels. This configuration allows for shear stress-free culture of cells, which is essential for delicate human cells.

The microdevices were fabricated in glass, as described in detail in the ESI. $\uparrow$ In short, the microfluidic features of the chip were fabricated in $0.21 \mathrm{~mm}$ glass, using an elaborate two-step wet etching process to successfully create structures with two different heights. Thereafter, the glass substrates were thermally bonded with $1.1 \mathrm{~mm}$ glass substrates with powder blasted via-holes. Finally, devices were diced in $2 \mathrm{~cm}$ square dies (Fig. 2B).

\section{Cell culture}

To demonstrate the possibility to perform live or time-lapse imaging, murine myoblastic C2C12 cells were cultured over 2 days and imaged using an automated DIC microscope (NIKON Ti Eclipse). C2C12 cells were cultured in Dulbecco'sMinimum Essential Medium (DMEM, Invitrogen) supplemented with $10 \%$ fetal bovine serum (FBS, Invitrogen), $100 \mathrm{mg} \mathrm{mL}$ penicillin and $100 \mathrm{mg} \mathrm{mL}^{-1}$ streptomycin (Pen/Strep, Invitrogen). After expansion culture, they were dissociated using trypsin (Invitrogen), resuspended to a concentration of approximately 5 million cells $\mathrm{mL}^{-1}$, and injected into the chip using a syringe through the cell loading channels into the

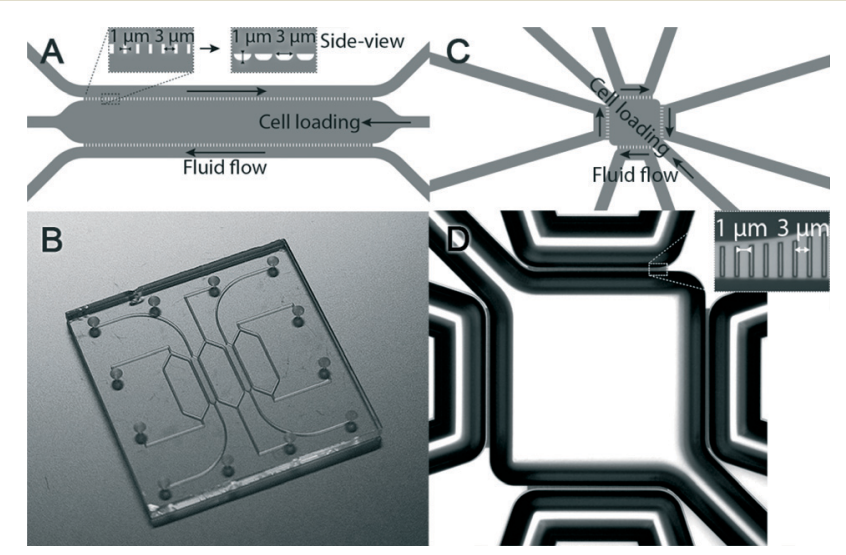

Fig. 2 (A) Schematic diagram of the rectangular chamber, showing the flow directions in the supply channels and cell loading channels, with an enlargement and side-view of the small channel array shown as inset. (B) Photograph of the $2 \mathrm{~cm}$ square die with two rectangular chambers. (C) Schematic diagram of the square chamber. (D) Bright-field microscopy image of a glass chip, depicting the chamber with the surrounding supply channels, with an enlargement of the smaller channels that connect the supply channel with the chamber shown as inset.

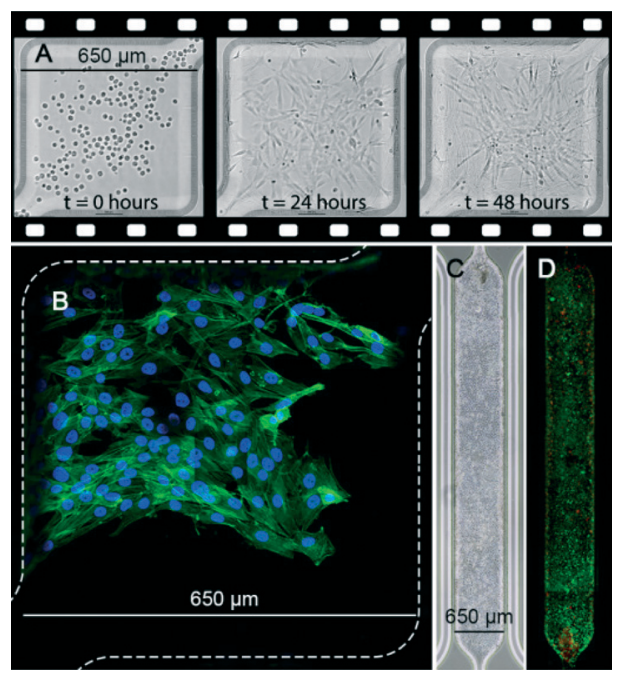

Fig. 3 (A) Bright-field microscopy images taken from 2 day time-lapse series of $\mathrm{C} 2 \mathrm{C} 12$ cells at different time points, with $t=0$ taken just after cell loading. (B) Confocal fluorescence microscopy image of MG63 cells in the square chamber after 2 days of proliferation, with stained nucleus (DNA, DAPI, blue) and cytoskeleton (F-actin, Phalloidin, green). (C) Bright-field microscopy stitched image of the rectangular chamber with Cho cells after 5 days of culture. (D) Epi-fluorescence image of the same Cho cells with live/dead staining, live cells being green and dead cells being red.

chamber. Cells were left to proliferate for 2 days, while flowing cell culture medium in the supply channels (single pass), at a flow rate of $8 \mu \mathrm{L} \mathrm{h}^{-1}$ using a precision syringe pump (Nexus Performance, Chemyx, USA). Fig. 3A presents snapshots taken from a 2 day time-lapse series on the growth of $\mathrm{C} 2 \mathrm{C} 12$ cells in the square chamber at different time points: at time point 0 , just after loading of the cells, and at time points 22 and $48 \mathrm{~h}$, where the attachment and spreading of cells can be observed, as well as the formation of a cell monolayer.

To demonstrate culture of more delicate human cells, osteoblastic MG-63 cells were cultured for 2 days, subsequently fluorescently stained with Phalloidin (cytoskeleton, F-actin) and DAPI (nuclei), and imaged by a fluorescence confocal microscope (NIKON Ti Eclipse with A1). MG-63 cells were cultured in $\alpha$ MEM supplemented with 10\% FBS and Pen/Strep. After culture, cells were rinsed with phosphate buffered saline (PBS, Invitrogen) and fixed with $4 \%$ paraformaldehyde (PFA, Sigma-Aldrich) for $10 \mathrm{~min}$, before being stained in situ by flushing the staining solutions through the chamber via the cell loading channels. As shown in Fig. 3B, MG63 cells were successfully stained inside the chip, which demonstrates the suitability of the platform for in situ cell staining and fluorescence imaging.

\section{Viability assay}

Cell viability was assessed using a standard live/dead assay on a Chinese hamster ovary (Cho) cell line, cultured in DMEM with 10\% FBS and Pen/Strep. All channels and the chamber were first flushed with PBS, and subsequently a mixture of 
$2 \mu \mathrm{M}$ calcein $\mathrm{AM}$ and $4 \mu \mathrm{M}$ ethidium homodimer-I (EthD-I, Invitrogen), to stain live and dead cells, respectively, was introduced into the chamber via the cell loading channels and left for $20 \mathrm{~min}$, before washing again with PBS. Samples were imaged using an epi-fluorescence microscope (TS100, NIKON, Japan), and overview images were created by stitching multiple images together. After 5 days of culture, in the rectangular culture chamber, the large majority of cells were found viable, with a few dead cells homogenously spread through the chamber (Fig. 3C-D), similar to conventional cell culture, proving that cells could be kept viable inside the platform for multiple days. Due to the seeding method, the entrance and exit of the chamber show slightly more red fluorescence due to cell debris flowing back from the deadvolume of the loading channels.

\section{Hypoxia assay}

Oxygen is a critical nutrient for cell survival, which is likely the first one to become limited due to its high uptake and low solubility. Therefore, it is frequently used as a model nutrient. ${ }^{12}$ When cells are subjected to low oxygen conditions (hypoxia), numerous genes are up- or down-regulated like angiogenesis related genes to promote cell survival. ${ }^{13}$ To study this, a Cho cell line (Cho HRE-GFP cells) transfected with a green fluorescence protein (GFP) hypoxia reporter was employed to demonstrate the ability of our microfluidic platform to recapitulate normal and hypoxia conditions. The cells fluoresce in case of limited availability of oxygen. More specifically, hypoxia-inducible factor-1 (HIF-1) translocates into the nucleus and binds to the hypoxia responsive element (HRE) promoter, thereby activating GFP transcription (for details on transfection and clonal procedure, please see the earlier work by Liu and co-workers). ${ }^{13}$

Cho cells were cultured in the chip, under normal $(20 \%)$ and reduced (4\%) oxygen conditions inside the chip holder, using regular culture medium supplied at a flow rate of $1 \mu \mathrm{L} \mathrm{h}^{-1}$ through the supply channels. Under these conditions, the residence time of $6 \mathrm{~h}$ was sufficient for the medium to reach equilibrium through the PFA tubing. The cells were introduced in the chamber by the cell loading channels and left to attach under normoxic conditions for $8 \mathrm{~h}$. Cell culture either continued at $20 \% \mathrm{O}_{2}$, or the culture condition was switched to hypoxic, whereby the gas mixture flowing in the chip holder contained approximately $4 \% \mathrm{O}_{2}$. After only $22 \mathrm{~h}$ of culture under hypoxia, cells showed increased expression of green fluorescence protein (Fig. 4D-F), demonstrating that by varying the oxygen level inside the chip holder, cells in the culture chamber of the chip are affected. In contrast, after $48 \mathrm{~h}$ of culture in normoxia, limited or no green fluorescence was observed (Fig. 4A-C), showing that under normal conditions, the cells inside the gas-impermeable glass chip have sufficient amount of oxygen not to turn to a hypoxic state. These results showed that the platform presented here can be utilized in a standalone fashion with chips made of gas-impermeable materials and that gas composition inside the chip can be varied for mimicking specific in vivo conditions, like hypoxia.

\section{Conclusions}

Here we have presented a standalone chip holder, particularly meant for microfluidic platforms made from gas-impermeable materials, to control the cell physical microenvironment without the necessity of using a separate incubator. The system is compatible with standard imaging laboratory equipment, making it suitable for live or time-lapse imaging. Various adherent cell types have been successfully cultured over a period of at least 5 days, and both stained and imaged in situ. The platform also proved to be suitable to control gas tension, e.g., to induce hypoxic conditions inside the microfluidic chip to reproduce in vivo conditions. In the future, this chip holder will particularly be applied to screen interactions between cells and biomaterials for regenerative medicine applications inside microfluidic platforms.

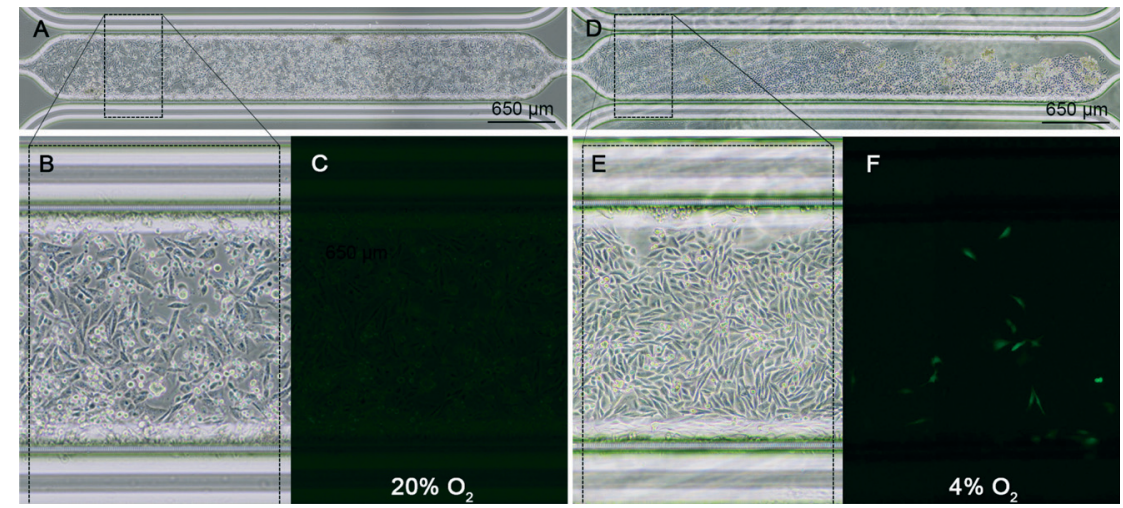

Fig. 4 Cho cells with hypoxia GFP reporter (green) inside a gas-impermeable glass chip, using the chip holder, after $48 \mathrm{~h}$ culture under normoxic conditions $\left(20 \% \mathrm{O}_{2}\right)$ on the left $(\mathrm{A}-\mathrm{C})$ and after $22 \mathrm{~h}$ under hypoxic conditions (approximately $4 \% \mathrm{O}_{2}$ ) on the right (D-F). For both experiments, the following images are provided: bright-field microscopy stitched overview image (NIKON TS100) of the rectangular chamber, with Cho cells inside $(A$ and $D)$; close-up of one section of the rectangular chamber ( $B$ and $E)$; and epi-fluorescence image of the same section of the culture chamber ( $C$ and F). After $48 \mathrm{~h}$ under normoxic conditions, limited or no fluorescence was observed (C), while under hypoxic conditions increased fluorescence was observed (F), indicating that the gene reporter is activated. 


\section{Acknowledgements}

We thank Prof. Masahiro Hiraoka from Kyoto University, Japan, for providing HRE-Luc plasmid DNA and Dr. Jun Liu, University of Twente, for creating HRE-GFP Cho cells. PH acknowledges financial support from Innovative Research Incentives Scheme Veni \#10236 of the Netherlands Organization for Scientific Research (NWO).

\section{Notes and references}

1 A. van der Meer and A. van den Berg, Integr. Biol., 2012, 4, 461-470.

2 B. Harink, et al., Lab Chip, 2013, 13, 3512-3528.

3 G. Mehta, et al., Biomed. Microdevices, 2007, 9, 123-134.
4 S. Oppegard and D. Eddington, Biomed. Microdevices, 2013, 15, 407-414.

5 C.-C. Peng, et al., Lab Chip, 2013, 13, 3239-3245.

6 D. Duffy, et al., Anal. Chem., 1998, 70, 4974-4984.

7 E. Berthier, E. Young and D. Beebe, Lab Chip, 2012, 12, 1224-1237.

8 A. Daar and H. Greenwood, J. Tissue Eng. Regener. Med., 2007, 1, 179-184.

9 M. Reichen, et al., PLoS One, 2012, 7, e52246.

10 T. Kirk and N. Szita, Biotechnol. Bioeng., 2013, 110, 1005-1019.

11 L. Hanson, et al., Microsc. Res. Tech., 2011, 74, 496-501.

12 J. Malda, et al., Biotechnol. Bioeng., 2004, 86, 9-18.

13 J. Liu, et al., J. Tissue Eng. Regener. Med., 2013, DOI: 10.1002/ term.1654. 